\title{
Comparison of body composition, bone mineral density and health-related physical fitness by physical activity levels in young women
}

\author{
Zhu-Jing Shen, Sung-Woo Kim, Jong-Kook Song, \& Hyo-Jung Kang* \\ Kyung Hee University
}

\begin{abstract}
[Purpose] The purpose of the study was to determine difference of body composition, bone mineral density and health-related fitness by physical activity level in young women. [Methods] A total of 90 women aged 19-29 years participated in this study. The subjects were divided into three groups (low, middle, and high level) according to the physical activity level estimated by bone-specific physical activity questionnaire(BPAQ). Body height and weight were measured. Body composition parameters including four sites of bone mineral density(BMD) were estimated by DXA (Hologic, QDR-4500, USA). Health-related fitness tests was assessed using sit \& reach, grip strength, sit-ups, and $\mathrm{VO}_{2 \max }$. Statistical analysis was performed using SAS version 9.4. All data were presented in terms of means and standard deviations. One-way ANOVA was applied to determine difference of dependent variables by physical activity level. Duncan's multiple range test was used as a post-hoc test. The statistical significance level was set at $p<.05$. [Results] There were significant differences on body weight $(\mathrm{F}=4.867, p=.01)$, body mass index $(\mathrm{F}=5.053$, $p=.008)$ and fat-free $\operatorname{mass}(\mathrm{F}=8.364, p=.0001)$ among the three groups. Significant differences were found on whole body $\operatorname{BMD}(\mathrm{F}=16.730, p=.0001)$, lumbar $\mathrm{BMD}(\mathrm{F}=11.480, p=.0001)$, femur $\operatorname{BMD}(\mathrm{F}=42.182, p=$ $.0001)$ and forearm $\operatorname{BMD}(\mathrm{F}=5.560, p=.005)$ among the three groups. There were also significant differences on sit and $\operatorname{reach}(\mathrm{F}=11.433, p=.0001)$, sit-ups $(\mathrm{F}=17.972, p=.0001), \mathrm{VO}_{2 \max }(\mathrm{F}=3.106, p=.05)$ and duration of $\mathrm{GXT}(\mathrm{F}=7.479, p=.001)$. [Conclusions] There were differences on body composition, bone mineral density and health-related physical fitness by physical activity levels. Nevertheless, the questionnaire used in this study was not able to judge participation in various exercise types including aerobic exercise or resistance exercise. Therefore, in the future study, longitudinal study considering various types of physical activity and dietary intake will be needed.
\end{abstract}

Key words: Bone-specific physical activity questionnaire, Body composition, Bone mineral density, Healthrelated physical fitness

\author{
서 론 \\ 세계보건기구에서는 전 세계적으로 성인의 약 $23 \%$ \\ (남성 $20 \%$, 여성 $27 \%$ )가 신체활동이 부족한 것으로 보 \\ 논문 투고일 : 2018. 06. 18. \\ 논문 수정일 : 2019. 01. 25. \\ 게재 확정일 : 2019. 04. 08. \\ * 교신저자 : 강효정 (khjtkd@khu.ac.kr). \\ * 이 논문은 2017년 대한민국 교육부와 한국연구재단의 지원을 \\ 받아 수행된 연구임(NRF-2017S1A5B5A07063370).
}

고하였고(WHO, 2011), 특히 젊은 성인 여성은 중년 여 성보다 신체활동이 부족한 것으로 나타났다(Hallal et al., 2012). 이러한 신체활동 부족은 주요 사망 위험요인인 골다공증, 당뇨병, 고혈압 등 만성질환 발병률을 증가시 키며(Kwan et al., 2012; Archer et al., 2011; Sattelmair et al., 2011; $\mathrm{WHO}, 2011)$, 관상동맥증, 뇌졸중과 같은 심 혈관질환에 부정적인 영향을 미친다(Smith et al., 2011; Yusuf et al., 2001). 심혈관 질환의 발병 위험은 신체활동 
량이 많은 사람들이 적은 사람들보다 남성은 $16 \%$, 여성 은 23\%가 낮으며(Hu et al., 2007; Li \& Siegtist, 2012), 규칙적인 신체활동 참여는 조기 사망률을 약 $20 \%$ 예방 할 수 있다 (Katzmarzyk et al., 2000). 그러나 남녀 성인 중 $85 \%$ 가 1 주일 동안 150 분 이상의 중강도 및 고강도 신체활동에 규칙적으로 참여하지 않는 것으로 보고하였 으며(Colley et al., 2011), 지난 10년간 신체활동 부족 으로 인한 질병 발병률은 감소되지 않고 있다(Arikawa et al., 2012; Barnett et al., 2007; Centers for Disease Control and Prevention, 1998). 또한 신체활동이 부족 한 20 대 성인들에게 비만, 심혈관 질환, 제 2 형 당뇨병과 같은 대사성질환 발병률이 증가하였다(Sacheck et al., 2010; Ogden et al., 2006; Duncan et al., 2004). 따라 서, 젊은 성인기부터 지속적인 신체활동 참여는 질병의 발병 위험을 감소시킬 뿐만 아니라 건강증진에 도움이 되며, 생애주기별 신체활동수준 관리가 필요하다.

신체구성은 연령, 식이섭취량, 신체활동량 등 다양한 요인에 의해 일생동안 변화하며, 일반적으로 성장기 이후 연령이 증가함에 따라 지방량은 증가하고 뼈의 무기질량 과 근육량은 감소한다(Newman et al., 2005; Hughes et al., 2002; Gallagher et al., 2000). 특히 근육량은 20 대 후반부터 점차 감소하기 시작하여 10 년마다 약 0.4 $0.8 \mathrm{~kg}$ 씩 감소한다(Maltais et al., 2009). 또한, 폐경 전 여성의 골밀도는 체중과 관련이 있으며, 특히 제지방량과 관련이 높은 것으로 나타났다(Saraví \& Sayegh, 2013). 여성의 경우 18 세경 최대 골 질량(peak bone mass)의 $90 \%$ 에 도달하고(Ferrari et al., 2012; Baxter-Jones et al., 2011), 폐경 전까지 골밀도는 지속적으로 점차 감소 하며 (Camacho et al., 2008), 폐경 후부터는 매년 0.5\% $\sim 1 \%$ 씩 급격히 감소한다(Camacho et al., 2008; Nordin et al., 1998). 이와 같이 젊은 성인기는 최대 빼 질량에 도 달하는 중요한 시기이며 신체활동 참여를 통해 높은 골밀 도를 유지하고 골 손실을 최소화하는 것이 중년기 이후 발생할 수 있는 골절이나 골다공증 발병 예방에 도움을 줄 수 있다(Choi et al., 2006; Heaney et al., 2000).

신체활동과 체력은 건강을 증진시키고 건강상태를 판 단하는 중요한 요인이며 (Sacheck et al., 2010), 연령의 증가와 신체활동 부족에 따라 건강 관련 체력이 떨어지고 일상적인 기능 저하가 발생하게 된다(Riebe et al., 2009; Tuna et al., 2009). 건강 관련 체력 중 심폐지구력의 지 표인 최대산소섭취량은 20대부터 30대까지 약 3\% 6\%
감소하게 되며(Fleg et al., 2005), 젊은 성인기부터 높은 수준의 심폐지구력 및 근육량 유지는 심혈관 질환 및 고 혈압, 당뇨병과 같은 대사질환의 발병률을 감소시킨다 (Sui et al., 2007; Newman et al., 2006; Gale et al., 2006; Katzmarzyk et al., 2004; Carnethon et al., 2003). 또한, 지속적인 신체활동 참여를 통한 체력 관리 는 심혈관 질환으로 인한 사망률을 감소시켜 수명에 긍 정적인 영향을 미친다(Faff, 2004). 이와 같이 건강 관련 체력은 신체의 건강을 평가할 수 있는 간접적인 지표이 며, 신체활동참여를 통하여 지속적인 관리가 필요하다.

따라서 본 연구의 목적은 젊은 성인 여성들을 대상으 로 신체활동 수준에 따른 신체구성, 골밀도, 건강관련체 력의 차이를 규명하는 것이다.

\section{연구방법}

\section{연구대상}

본 연구대상자는 경기도 $\mathrm{Y}$ 시에 소재한 $\mathrm{K}$ 대학교에서 자발적으로 연구에 참여를 희망하는 건강한 만 $19 \sim 29$ 세 성인 여성을 무작위로 선발하였다. 본 연구는 최초 104 명이 연구에 참여하였으나, 대상자의 개인적 사유와 신체 활동 제한으로 인하여 측정에 참여하지 못한 14 명을 제 외시켰고 최종적으로 총 90 명이 연구에 참여하였다. 대 상자 제외 기준은 첫째, 연구 시작 3 개월 이내 심혈관계 약물을 복용한 자, 둘째, 연구 시작 3 개월 이내 정형외과 수술을 받은 자, 셋째, 최근 6 개월 동안 2 회 이상의 $\mathrm{X}$-선 검사를 받은 자를 제외하였다. 본 연구는 $\mathrm{K}$ 대학교 생명 윤리심의위원회에서 승인을 받은 후 진행하였다 $\mathrm{KHS}$ IRB-17-048). 연구대상자들의 신체적인 특성은 (Table 1 과 같다.

\section{측정 항목 및 방법}

\section{체격}

대상자의 신장과 체중은 신장계(T.K.K. 11253: Takei Scientific Ins Co., Japan)와 표준 체중계 (Cas 150A, Korea)를 이용하여 측정하였고, 체질량지수(body mass index; BMI)를 산출하였다. 인체측정용 줄자를 이용하 여 허리둘레와 엉덩이둘레를 측정한 후 허리-엉덩이 둘 
Table 1. Characteristic of the subjects

$(\mathrm{Mean} \pm \mathrm{SD})$

\begin{tabular}{|c|c|c|c|c|}
\hline Variables & $\begin{array}{c}\text { Low } \\
(\mathrm{n}=30)\end{array}$ & $\begin{array}{l}\text { Middle } \\
(\mathrm{n}=30)\end{array}$ & $\underset{(n=30)}{\text { High }}$ & $F$-value \\
\hline \multirow{2}{*}{ Age (yrs) } & $24.03 \pm 2.40$ & $23.20 \pm 2.45$ & $22.48 \pm 2.85$ & \multirow{2}{*}{2.721} \\
\hline & $\mathrm{a}$ & $\mathrm{a}$ & $\mathrm{a}$ & \\
\hline \multirow{2}{*}{ Body height (cm) } & $161.57 \pm 3.17$ & $163.23 \pm 5.04$ & $161.39 \pm 5.47$ & \multirow{2}{*}{1.419} \\
\hline & $\mathrm{a}$ & $\mathrm{a}$ & $\mathrm{a}$ & \\
\hline \multirow{2}{*}{ Body weight (cm) } & $53.24 \pm 5.68$ & $58.63 \pm 8.55$ & $57.37 \pm 6.43$ & \multirow{2}{*}{$4.867^{* *}$} \\
\hline & a & $\mathrm{b}$ & $\mathrm{b}$ & \\
\hline \multirow{2}{*}{ BMI $\left(\mathrm{kg} / \mathrm{m}^{2}\right)$} & $20.38 \pm 1.90$ & $21.95 \pm 2.59$ & $22.03 \pm 2.38$ & \multirow{2}{*}{$5.053^{* * *}$} \\
\hline & a & $\mathrm{b}$ & $\mathrm{b}$ & \\
\hline \multirow{2}{*}{ WHR } & $0.74 \pm 0.04$ & $0.76 \pm 0.05$ & $0.74 \pm 0.03$ & \multirow{2}{*}{2.798} \\
\hline & $\mathrm{a}$ & $\mathrm{a}$ & $\mathrm{a}$ & \\
\hline
\end{tabular}

Same alphabet indicates no significant difference among groups

BMI: body mass index; WHR: waist-to-hip ratio

${ }^{*} p<.05,{ }^{* *} p<.01,{ }^{* * *} p<.001$

레 비율(waist-hip ratio; WHR)을 산출하였다.

\section{신체구성과 골밀도}

신체구성과 골밀도는 Dual X-ray Absorptiometry (DXA, QDR-4500W, Hologic, USA)를 이용하여 전신의 체지방량(fat mass), 제지방량(fat-free mass), 체지방률 (percent body fat), 골밀도(bone mineral density)를 측정하였다. 또한 골밀도는 신체 4부위(전신, 요추, 대퇴, 전완)를 측정하였으며, $\mathrm{g} / \mathrm{cm}^{2}$ 단위로 기록하였다.

\section{건강 관련 체력}

건강 관련 체력은 유연성, 근력, 근지구력, 심폐지구력 을 포함한 4개의 요인을 앉아 윗몸 앞으로 굽히기, 악력, 윗몸일으키기, 최대산소섭취량 순으로 측정하였다.

최대산소섭취량은 가스대사분석기(Quark b2: Cosmed, Italy)를 이용하여 트레드밀에서 Bruce protocol을 적용 하여 실시하였다. 대상자의 All-out 판단 기준은 아래와 같다. 운동자각도 $(\mathrm{RPE})$ 의 값이 17 이상이거나 예측된 심 박수가 최대 심박수의 $90 \%$ 이상을 초과하거나 호흡교 환율이 1.10 보다 클 때 측정을 중지하였다.

\section{뼈 관련 신체활동}

빼 건강에 영향을 미칠 수 있는 신체활동량을 측정하 기 위해 Weeks와 Beck(2008)가 개발한 설문지(Bonespecific Physical Activity Questionnaire)를 사용하였
다. 신체활동량 설문지는 운동 종목과 기간에 따라 과 거 $\mathrm{BPAQ}$ (1세부터 현재 시점 1년 전까지 참여한 신체활 동량)와 현재 $\mathrm{BPAQ}$ (현재 시점 1년 전부터 현재까지 참 여한 신체활동량)로 구성되었다. 또한 과거부터 현재까 지 일상적 활동에 대해서 뼈에 영향을 미치는 기계적인 부하를 시간별 및 연령별로 검사하였다. $\mathrm{BPAQ}$ 설문지 를 통해 조사한 신체활동량을 Weeks와 Beck에 제시된 소프트웨어 프로그램으로(http://www.fithdysign.com) 산출하였고, 총 26 개 운동유형과 총 145 개 운동 종목의 신체활동을 측정하였다. 또한, Weeks 등(2011)의 연구에 서 제시한 $\mathrm{BPAQ}$ 설문지의 신뢰도 계수는 매우 높은 것으 로 나타났으며 (inter-tester: 0.92, intra-tester: 0.97), $\mathrm{BPAQ}$ 설문지 점수에 따라 percentile을 적용하여 세 그 룹으로(low, middle, high) 분류하였다〈Table 2〉.

Table 2. Bone-specific physical activity scores among the three groups

$($ Mean \pm SD)

\begin{tabular}{lccc}
\hline \hline Variables & $\begin{array}{c}\text { Low } \\
(\mathrm{n}=30)\end{array}$ & $\begin{array}{c}\text { Middle } \\
(\mathrm{n}=30)\end{array}$ & $\begin{array}{c}\text { High } \\
(\mathrm{n}=30)\end{array}$ \\
\hline pBPAQ score & $4.8 \pm 3.46$ & $30.8 \pm 14.05$ & $67.9 \pm 20.34$ \\
\hline cBPAQ score & $0.9 \pm 1.51$ & $5.1 \pm 6.07$ & $14.9 \pm 9.42$ \\
\hline tBPAQ score & $2.9 \pm 1.81$ & $17.9 \pm 6.68$ & $41.4 \pm 11.64$
\end{tabular}

p: past; c: current: $t$ : total; BPAQ: bone-specific physical activity questionnaire 


\section{통계 처리}

모든 자료는 SAS software version 9.4(SAS Institute, Cary, $\mathrm{NC}$ )를 이용하여 분석하였으며, 모든 변인은 기술 통계를 이용하여 평균(mean)과 표준편차(standard deviation)를 산출하였다. $\mathrm{BPAQ}$ 의 점수에 따른 신체구성, 골밀도, 건강관련체력의 차이를 비교하기 위하여 일원분 산분석을 실시하였다. 사후검증으로 Duncun's multiplerange test를 적용하였고, 모든 통계 처리의 유의수준 $(\alpha)$ 은 .05로 설정하였다.

\section{연구결과}

\section{신체구성}

신체활동수준에 따른 신체구성을 비교 분석한 결과는
〈Table 3〉에 제시된 바와 같다. 신체활동이 낮은 그룹이 중간과 높은 그룹보다 제지방량 $(p<0.0001)$ 에서 통계적 으로 유의하게 낮게 나타났으나 체지방량, 체지방률에서 는 신체활동수준에 따른 세 그룹 간 통계적으로 유의한 차이가 없었다.

\section{골밀도}

신체활동수준에 따른 골밀도를 비교 분석한 결과는 〈Table 4〉에 제시된 바와 같다. 신체활동이 높은 그룹이 중간 그룹과 낮은 그룹보다 전신 골밀도 $(p<0.0001)$ 와 전완골밀도 $(p<0.01)$ 가 통계적으로 유의하게 높은 것으 로 나타났고, 요추 골밀도 $(p<0.0001)$ 는 신체활동이 낮 은 그룹이 중간과 높은 신체활동그룹보다 통계적으로 유 의하게 낮게 나타났다. 한편, 대퇴 골밀도 $(p<0.0001)$ 는 신체활동이 높은, 중간, 낮은 그룹 순으로 통계적으로 유

Table 3. Comparison of body composition among the three groups

$(\mathrm{Mean} \pm \mathrm{SD})$

\begin{tabular}{|c|c|c|c|c|}
\hline Variables & $\begin{array}{c}\text { Low } \\
(\mathrm{n}=30)\end{array}$ & $\begin{array}{l}\text { Middle } \\
(\mathrm{n}=30)\end{array}$ & $\begin{array}{l}\text { High } \\
(\mathrm{n}=30)\end{array}$ & $F$-value \\
\hline \multirow{2}{*}{ Fat mass (kg) } & $15.12 \pm 4.42$ & $17.41 \pm 4.80$ & $15.71 \pm 4.37$ & \multirow{2}{*}{2.066} \\
\hline & $\mathrm{a}$ & $\mathrm{a}$ & $\mathrm{a}$ & \\
\hline \multirow{2}{*}{ Fat-free mass (kg) } & $35.13 \pm 2.20$ & $38.12 \pm 4.50$ & $38.56 \pm 3.49$ & \multirow{2}{*}{$8.364^{* * * *}$} \\
\hline & $\mathrm{a}$ & $\mathrm{b}$ & $\mathrm{b}$ & \\
\hline \multirow{2}{*}{ Percent body fat (\%) } & $28.50 \pm 5.68$ & $29.78 \pm 5.01$ & $27.48 \pm 5.11$ & \multirow{2}{*}{1.435} \\
\hline & $\mathrm{a}$ & $\mathrm{a}$ & $\mathrm{a}$ & \\
\hline
\end{tabular}

Same alphabet indicates no significant difference among groups

${ }^{*} p<.05,{ }^{* *} p<.01,{ }^{* * *} p<.001,{ }^{* * * *} p<.0001$

Table 4. Comparison of bone mineral density among the three groups

$(\mathrm{Mean} \pm \mathrm{SD})$

\begin{tabular}{|c|c|c|c|c|}
\hline Variables & $\begin{array}{c}\text { Low } \\
(\mathrm{n}=30)\end{array}$ & $\begin{array}{c}\text { Middle } \\
(\mathrm{n}=30)\end{array}$ & $\begin{array}{c}\text { High } \\
(\mathrm{n}=30)\end{array}$ & $F$-value \\
\hline \multirow{2}{*}{ Whole body BMD $\left(\mathrm{g} / \mathrm{cm}^{2}\right)$} & $1.08 \pm 0.07$ & $1.11 \pm 0.05$ & $1.17 \pm 0.07$ & \multirow{2}{*}{$16.730^{* * * *}$} \\
\hline & $\mathrm{a}$ & $\mathrm{a}$ & $\mathrm{b}$ & \\
\hline \multirow{2}{*}{ Lumbar BMD (g/cm²) } & $0.93 \pm 0.10$ & $1.01 \pm 0.08$ & $1.05 \pm 0.11$ & \multirow{2}{*}{$11.480^{* * * *}$} \\
\hline & $\mathrm{a}$ & $\mathrm{b}$ & $\mathrm{b}$ & \\
\hline \multirow{2}{*}{ Femur BMD $\left(\mathrm{g} / \mathrm{cm}^{2}\right)$} & $0.83 \pm 0.09$ & $0.93 \pm 0.05$ & $1.03 \pm 0.10$ & \multirow{2}{*}{$42.182^{* * * *}$} \\
\hline & $\mathrm{a}$ & $\mathrm{b}$ & $\mathrm{c}$ & \\
\hline \multirow{2}{*}{ Forearm BMD $\left(\mathrm{g} / \mathrm{cm}^{2}\right)$} & $0.54 \pm 0.03$ & $0.55 \pm 0.04$ & $0.57 \pm 0.03$ & \multirow{2}{*}{$5.560^{* *}$} \\
\hline & $\mathrm{a}$ & $\mathrm{a}$ & $\mathrm{b}$ & \\
\hline
\end{tabular}

Same alphabet indicates no significant difference among groups

BMD: bone mineral density

${ }^{*} p<.05,{ }^{* *} p<.01,{ }^{* * *} p<.001,{ }^{* * * *} p<.0001$ 
의하게 높았다.

\section{건강 관련 체력}

신체활동수준에 따른 건강 관련 체력을 비교 분석한 결과는 〈Table 5)에 제시된 바와 같다. 신체활동이 높은 그룹은 중간 그룹과 낮은 그룹 보다 앉아 윗몸 앞으로 굽 히기 $(p<0.0001)$ 와 운동 시간 $(p<0.001)$ 이 통계적으로 유의하게 높았으나, 윗몸일으키기 $(p<0.0001)$ 에서는 신 체활동이 낮은 그룹이 중간 그룹과 높은 그룹보다 통계적 으로 유의하게 낮게 나타났다. 최대산소섭취량 $(p<0.05)$ 은 신체활동이 낮은 그룹과 높은 그룹 간에 통계적으로 유의한 차이가 나타났으나, 악력과 최대심박수에서는 세 그룹 간에 통계적으로 유의한 차이가 없었다.

\section{논 의}

본 연구에서 신체활동수준이 높은 그룹, 중간 그룹이 낮은 그룹보다 체중, $\mathrm{BMI}$ 는 통계적으로 유의하게 높게 나타났고, 제지방량은 신체활동수준이 낮은 그룹이 중 간과 높은 그룹보다 유의하게 낮게 나타났으나, 신체활
동수준에 따른 세 그룹 간 신장, $\mathrm{WHR}$, 체지방량, 체지방 률에서는 유의한 차이가 없었다. Donnelly et al.(2003) 의 연구에서도 신체활동수준이 높은 여성과 낮은 여성 의 체지방량과 체지방률의 차이가 나타나지 않아 본 연 구 결과와 일치하고 있다. 그러나 Kyle et al.(2004)은 Minnesota Leisure Time Activities Questionnaire를 이용하여 건강한 성인 여성의 BMI를 분석한 결과 신체활 동수준이 높은 여성이 낮은 여성보다 낮게 나타나 본 연구 와 상반된 결과를 보였다. Weeks et al.(2016)은 BPAQ 설문지를 이용하여 건강한 성인 남녀의 신체활동수준을 조사한 결과 신체활동수준이 높을수록 WHR이 낮게 나 타났다고 보고하였다. 또한 중년 여성을 대상으로 보수계 를 이용하여 신체활동수준에 따른 연구 결과에 따르면 신체활동수준이 높은 여성의 BMI, 체지 방률, $\mathrm{WHR}$ 은 신 체활동수준이 낮은 여성보다 낮게 나타났다(Thompson et al., 2004). 이와 같이 연구에 따라 신체활동수준별 신 체구성의 결과는 다소 다르게 나타나며, 연구목적에 적합 한 신체활동수준 평가 도구를 사용해야 할 것으로 사료 된다.

본 연구에서 신체활동수준이 높은 그룹은 중간 그룹과 낮은 그룹의 여성보다 전신 골밀도와 전완 골밀도가 통 계적으로 유의하게 높은 것으로 나타났으며, 요추 골밀도

Table 5. Comparison of health-related physical fitness among the three groups

$(\mathrm{Mean} \pm \mathrm{SD})$

\begin{tabular}{|c|c|c|c|c|}
\hline Variables & $\begin{array}{c}\text { Low } \\
(n=30)\end{array}$ & $\begin{array}{l}\text { Middle } \\
(\mathrm{n}=30)\end{array}$ & $\underset{(n=30)}{\text { High }}$ & $F$-value \\
\hline \multirow{2}{*}{ Sit \& reach $(\mathrm{cm})$} & $9.52 \pm 10.24$ & $10.36 \pm 10.83$ & $20.63 \pm 8.90$ & \multirow{2}{*}{$11.433^{* * * *}$} \\
\hline & $\mathrm{a}$ & $\mathrm{a}$ & $\mathrm{b}$ & \\
\hline \multirow{2}{*}{ Grip strength (kg) } & $26.05 \pm 4.60$ & $27.53 \pm 4.78$ & $27.92 \pm 4.15$ & \multirow{2}{*}{1.431} \\
\hline & $\mathrm{a}$ & $\mathrm{a}$ & $\mathrm{a}$ & \\
\hline \multirow{2}{*}{ Sit-ups (n) } & $16.40 \pm 11.33$ & $26.80 \pm 9.98$ & $31.67 \pm 8.75$ & \multirow{2}{*}{$17.972^{* * * *}$} \\
\hline & $\mathrm{a}$ & $\mathrm{b}$ & $\mathrm{b}$ & \\
\hline \multirow{2}{*}{$\mathrm{VO}_{2 \max }(\mathrm{ml} / \mathrm{kg} / \mathrm{min})$} & $35.66 \pm 4.65$ & $36.24 \pm 5.28$ & $38.92 \pm 6.16$ & \multirow{2}{*}{$3.106^{*}$} \\
\hline & $\mathrm{a}$ & $\mathrm{ab}$ & $\mathrm{b}$ & \\
\hline \multirow{2}{*}{$\mathrm{HR}_{\max }$ (beats/min) } & $182.67 \pm 8.40$ & $182.60 \pm 12.52$ & $185.80 \pm 8.38$ & \multirow{2}{*}{1.012} \\
\hline & $\mathrm{a}$ & $\mathrm{a}$ & $\mathrm{a}$ & \\
\hline \multirow{2}{*}{ Duration of GXT (min) } & $9.08 \pm 1.05$ & $9.22 \pm 1.21$ & $10.25 \pm 1.53$ & \multirow{2}{*}{$7.479^{* * *}$} \\
\hline & $\mathrm{a}$ & $\mathrm{a}$ & $\mathrm{b}$ & \\
\hline
\end{tabular}

Same alphabet indicates no significant difference among groups

$\mathrm{VO}_{2 \max }$ : maximum oxygen uptake; $\mathrm{HR}_{\max }$ : maximum heart rate; GXT: graded exercise test

${ }^{*} p<.05, \quad p<.01,{ }^{* * *} p<.001,{ }^{* * * *} p<.0001$ 
는 신체활동수준이 낮은 그룹은 중간 그룹과 높은 그룹의 여성보다 통계적으로 유의하게 낮게 나타났다. 한편 대퇴 골밀도는 신체활동수준이 높은 그룹의 여성이 가장 높게 나타났으며, 높은 그룹, 중간 그룹, 낮은 그룹 순으로 통 계적으로 유의한 차이가 나타났다. 이와 같은 결과는 높 은 신체활동수준이 대퇴 골밀도와 요추 골밀도 증가에 영향을 미친다는 선행연구와 일치한다(Kim et al., 2016; Weeks et al., 2016; Bolam et al., 2014). Kemper et al . (2000)은 건강한 젊은 성인을 대상으로 높은 신체활동 수준이 높은 요추 골밀도 및 대퇴 골밀도와 관련이 있다 고 보고하였다. Morseth et al. (2010)의 연구에서도 건 강한 성인 여성은 높은 신체활동수준이 높은 대퇴 골밀 도와 밀접한 관련이 있다고 보고하였다. 또한 중년 여 성을 대상으로 신체활동수준에 따른 골밀도를 비교한 결 과 높은 신체활동수준이 낮은 신체활동수준보다 요추 골 밀도, 대퇴 골밀도, 그리고 전신 골밀도가 높게 나타났다 (Hsu et al., 2006; Kelley, 1998a; Kelley, 1998b). 나아 가 젊은 성인 여성을 대상으로 22년 동안 종단 연구한 결 과 젊은 성인 시기에 높은 신체활동수준으로 골밀도가 높은 여성은 노년기에 발생하는 골다공증 위험성이 낮은 것으로 나타났다(Morseth et al., 2010; Nilsson et al., 2008; Ilich-Ernst et al., 2002). 따라서 신체활동수준 이 낮고 연령이 증가할수록 골밀도가 감소함으로써 발생 하는 골감소증과 골다공증을 예방하기 위해서는 고충격 운동을 포함한 다양한 신체활동참여가 필요하다(Liu et al., 2003; Cheng et al., 2002; Bassey et al., 1998; Kohrt et al., 1997; Heinonen et al., 1996; Bassey et al., 1994).

본 연구에서 신체활동수준이 높은 그룹의 여성은 중간 그룹과 낮은 그룹의 여성들 보다 앉아 윗몸 앞으로 굽히 기와 운동 시간이 유의하게 높았으나, 윗몸일으키기에서 는 신체활동수준이 낮은 여성들이 중간 그룹과 높은 그 룹의 여성들보다 유의하게 낮게 나타났다. 최대산소섭취 량은 신체활동수준이 낮은 여성들과 높은 여성들 간에 통 계적으로 유의한 차이가 있었지만, 악력과 최대심박수에 서는 신체활동수준에 따른 세 그룹 간에 통계적으로 유의 한 차이가 없었다. 선행연구에서도 신체활동수준이 높은 젊은 성인 여성은 신체활동수준이 낮은 여성보다 최대 산소섭취량이 높게 나타났으며 (Donnelly et al., 2003), 높은 심폐지구력은 최대 산소섭취량이 높은 신체활동 수 준과 밀접한 관련이 있다고 보고하였다(Church et al.,
2007). 또한 연령의 증가에 따라 여성의 근지구력과 심 폐지구력이 감소하고, 높은 신체활동수준이 높은 체력과 밀접한 관련이 있으며, 건강에 긍정적인 영향을 미친다고 보고하였다(Blair et al., 2001). 일반적으로 체력은 젊은 성인 시기에 최고 수준에 도달한 후 중년기부터 급격하게 감소함으로 (Deforche et al., 2003) 젊은 성인의 건강 관 련 체력을 극대화할 수 있도록 신체활동참여를 통해 높 은 체력수준에 도달하는 것이 무엇보다 중요하다.

\section{결론 및 제언}

본 연구는 만 19-29세 성인 여성 총 90명을 대상으 로 신체활동수준에 따른 신체구성, 골밀도, 건강 관련 체 력의 차이를 분석한 결과 다음과 같은 결론을 얻었다.

제지방량의 경우 신체활동수준이 낮은 여성들은 중 간 그룹과 높은 그룹의 여성들보다 유의하게 낮았다. 전 신 골밀도와 전완 골밀도의 경우 신체활동수준이 높은 여 성들은 낮은 그룹과 중간 그룹의 여성들보다 유의하게 높 았다. 요추 골밀도는 신체활동수준이 낮은 여성들이 중간 그룹과 높은 그룹의 여성들보다 유의하게 낮았다. 대퇴 골밀도의 경우 신체활동수준이 낮은 여성들은 중간 그룹 과 높은 그룹의 여성들보다 유의하게 낮았다. 건강 관련 체력의 경우 악력과 최대심박수에서 신체활동수준에 따 른 세 그룹 간 유의한 차이가 나타나지 않았으나, 앉아 윗 몸 앞으로 굽히기와 운동 시간은 신체활동수준이 높은 여 성들은 낮은 그룹과 중간 그룹의 여성들보다 유의하게 높 았다. 윗몸일으키기는 신체활동수준이 낮은 여성들은 중 간 그룹과 높은 그룹의 여성들보다 유의하게 낮았다. 최 대산소섭취량의 경우 신체활동수준이 낮은 여성들은 높 은 그룹의 여성들보다 유의하게 낮았다. 이상에서 알 수 있듯이 $\mathrm{BPAQ}$ 설문지 조사를 통해서 제지방량, 골밀도와 건강관련체력의 경우 신체활동수준이 높은 여성들은 신 체활동수준이 낮은 여성들보다 유의하게 높게 나타났으 나 체지방량, 체지방률, 악력에서는 신체활동수준에 따 른 유의한 차이가 없었다.

따라서 본 연구에서 $\mathrm{BPAQ}$ 를 이용한 신체활동 조사는 성인 여성의 골밀도와 건강 관련 체력의 차이를 규명할 수 있었으나, 체지방률, 체지방량과 WHR의 관련성을 분 석하는데 다소 미흡한 것으로 나타났다. 즉 본 연구에서 사용한 설문지는 유산소운동 혹은 저항성 운동을 포함하 
는 다양한 운동유형에 참여 여부를 판단할 수 없었기 때 문에 나타난 것으로 추후 연구에서는 여러 신체활동 유 형과 식이 섭취를 고려한 종단연구가 필요할 것으로 사 료된다.

\section{참고문헌}

Archer, E., \& Blair, S. N. (2011). Physical activity and the prevention of cardiovascular disease: from evolution to epidemiology. Progress in cardiovascular diseases, 53(6), 387-396.

Arikawa, A. Y., O’Dougherty, M., Kaufman, B. C., Schmitz, K. H., \& Kurzer, M. S. (2012). Attrition and adherence of young women to aerobic exercise: Lessons from the WISER study. Contemporary clinical trials, 33(2), 298-301.

Barnett, T. A., Gauvin, L., Craig, C. L., \& Katzmarzyk, P. T. (2007). Modifying effects of sex, age, and education on 22-year trajectory of leisure-time physical activity in a Canadian cohort. Journal of Physical Activity and Health, 4(2), 153-166.

Bassey, E. J., \& Ramsdale, S. J. (1994). Increase in femoral bone density in young women following high-impact exercise. Osteoporosis International, 4(2), 72-75.

Bassey, E. J., Rothwell, M. C., Littlewood, J. J., \& Pye, D. W. (1998). Pre- and postmenopausal women have different bone mineral density responses to the same high-impact exercise. Journal of Bone and Mineral Research, 13(12), 1805-1813.

Baxter-Jones, A. D., Faulkner, R. A., Forwood, M. R., Mirwald, R. L., \& Bailey, D. A. (2011). Bone mineral accrual from 8 to 30 years of age: an estimation of peak bone mass. Journal of Bone and Mineral Research, 26(8), 1729-1739.

Blair, S. N., Cheng, Y., \& Holder, J. S. (2001). Is physical activity or physical fitness more important in defining health benefits? Medicine \& Science in Sports \& Exercise, 33(6), S379-S399.

Bolam, K. A., Beck, B. R., Adlard, K. N., Skinner, T. L., Cormie, P., Galvao, D. A., Spry, N., Newton, R. U., \& Taaffe, D. R. (2014). The relationship between BPAQ-derived physical activity and bone density of middle-aged and older men. Osteoporosis International, 25(11), 2663-2668.

Camacho, P. M., Dayal, A. S., Diaz, J. L., Nabhan, F. A., Agarwal, M., Norton, J. G., Robinson, P. A., \& Albain, K. S. (2008). Prevalence of secondary causes of bone loss among breast cancer patients with osteopenia and osteoporosis. Journal of Clinical Oncology, 26(33), 5380-5385.

Carnethon, M. R., Gidding, S. S., Nehgme, R., Sidney, S., Jacobs Jr., D. R., \& Liu, K. (2003). Cardiorespiratory fitness in young adulthood and the development of cardiovascular disease risk factors. Journal of American Medical Association, 290(23)

Centers for Disease Control and Prevention (1998). BRFSS summary prevalence report. Atlanta: Behavioral Surveillance Branch, Office of Surveillance and Analysis. National Center for Chronic Disease Prevention and Health Promotion Centers for Disease Control and Prevention.

Cheng, S., Sipilä, S., Taaffe, D. R., Puolakka, J., \& Suominen, H. (2002). Change in bone mass distribution induced by hormone replacement therapy and high-impact physical exercise in post-menopausal women. Bone, 31(1), 126-135.

Choi, M. J., Lee, U. J., \& Jung, Y. J. (2006). Relations of exercise, body composition, blood pressure and bone mineral density in adult women. Korean Journal of Exercise Nutrition, 10(3), 243-253.

Church, T. S., Earnest, C. P., Skinner, J. S., \& Blair, S. N. (2007). Effects of different doses of physical activity on cardiorespiratory fitness among sedentary, overweight or obese postmenopausal women with elevated blood pressure: A randomized controlled trial. Journal of American Medical Association, 297(19), 2081-2091.

Colley, R. C., Garriguet, D., Janssen, I., Craig, C. L., Clarke, J., \& Tremblay, M. S. (2011). Physical activity of Canadian adults: accelerometer results from the 2007 to 2009 Canadian Health Measures Survey. Health Reports, 22(1), 7.

Deforche, B., Lefevre, J., Bourdeaudhuij, I., Hills, A. P., Duquet, W., \& Bouckaert, J. (2003). Physical fitness and physical activity in obese and nonobese Flemish youth. Obesity, 11(3), 434-441.

Donnelly, J. E., Hill, J. O., Jacobsen, D. J., Potteiger, J., Sullivan, D. K., Johnson, S. L., Heelan, K., Hise, M., Fennessey, P. V., Sonko, B., \& Sharp, T. (2003). Effects of a 16-month randomized controlled exercise trial on body weight and composition in young, overweight men and women: The Midwest Exercise Trial. Archives of Internal Medicine, 163(11), 1343-1350.

Duncan, G. E., Li, S. M., \& Zhou, X. H. (2004). Prevalence and trends of a metabolic syndrome phenotype among US adolescents, 1999-2000. Diabetes Care, 27(10), 2438-2443.

Faff, J. (2004). Physical activity, physical fitness, and longevity. 
Biology of Sport, 21(1), 3-24.

Ferrari, S., Bianchi, M. L., Eisman, J. A., Foldes, A. J., Adami, S., Wahl, D. A., Stepan, J. J., de Vernejoul, M. C., Kaufman, J. M., \& IOF Committee of Scientific Advisors Working Group on Osteoporosis Pathophysiology. (2012). Osteoporosis in young adults: Pathophysiology, diagnosis, and management. Osteoporosis International, 23(12), 2735-2748.

Fleg, J. L., Morrell, C. H., Bos, A. G., Brant, L. J., Talbot, L. A., Wright, J. G., \& Lakatta, E. G. (2005). Accelerated longitudinal decline of aerobic capacity in healthy older adults. Circulation Journal, 112(5), 674-682.

Gale, C. R., Martyn, C. N., Cooper, C., \& Sayer, A. A. (2006). Grip strength, body composition, and mortality. International Journal of Epidemiology, 36(1), 228-235.

Gallagher, D., Ruts, E., Visser, M., Heshka, S., Baumgartner, R. N., Wang, J., Pierson, R. N., Pi-Sunyer, F. X., \& Heymsfield, S. B. (2000). Weight stability masks sarcopenia in elderly men and women. American Journal of Physiology-Endocrinology and Metabolism, 279(2), E366-E375.

Hallal, P. C., Andersen, L. B., Bull, F. C., Guthold, R., Haskell, W., Ekelund, U., \& Lancet Physical Activity Series Working Group. (2012). Global physical activity levels: Surveillance progress, pitfalls, and prospects. The Lancet, 380(9838), 247-257.

Heaney, R. P., Abrams, S., Dawson-Hughes, B., Looker, A., Marcus, R., Matkovic, V., \& Weaver, C. (2000). Peak bone mass. Osteoporosis international, 11(12), 985-1009.

Heinonen, A., Kannus, P., Sievänen, H., Oja, P., Pasanen, M., Rinne, M., Uusi-Rasi, K., \& Vuori, I. (1996). Randomised controlled trial of effect of high-impact exercise on selected risk factors for osteoporotic fractures. The Lancet, 348(9038), 1343-1347.

Hsu, Y. H., Venners, S. A., Terwedow, H. A., Feng, Y., Niu, T., Li, Z., Laird, N., Brain, J. D., Cummings, S. R., Bouxsein, M. L., \& Rosen, C. J. (2006). Relation of body composition, fat mass, and serum lipids to osteoporotic fractures and bone mineral density in Chinese men and women. The American Journal of Clinical Nutrition, 83(1), 146-154.

Hu, G., Jousilahti, P., Borodulin, K., Barengo, N. C., Lakka, T. A., Nissinen, A., \& Tuomilehto, J. (2007). Occupational, commuting and leisure-time physical activity in relation to coronary heart disease among middle-aged Finnish men and women. Atherosclerosis, 194(2), 490-497.

Hughes, V. A., Frontera, W. R., Roubenoff, R., Evans, W. J., \& Singh, M. A. F. (2002). Longitudinal changes in body com- position in older men and women: Role of body weight change and physical activity. The American Journal of Clinical Nutrition, 76(2), 473-481.

Ilich-Ernst, J., \& Brownbill, R. A. (2002). Critical factors for bone health in women across the age span: how important is muscle mass? Ariel, 146, 65-22.

Katzmarzyk, P. T., Gledhill, N., \& Shephard, R. J. (2000). The economic burden of physical inactivity in Canada. Canadian Medical Association Journal, 163(11), 1435-1440.

Kelley, G. (1998a). Aerobic Exercise and Lumbar Spine Bone Mineral Density in Postmenopausal Women: AMeta-analysis. Journal of the American Geriatrics Society, 46(2), 143-152.

Kelley, G. A. (1998b). Aerobic exercise and bone density at the hip in postmenopausal women: A meta-analysis. Preventive Medicine, 27(6), 798-807.

Kemper, H. C. G., Twisk, J. W. R., Van Mechelen, W., Post, G. B., Roos, J. C., \& Lips, P. T. A. M. (2000). A fifteen-year longitudinal study in young adults on the relation of physical activity and fitness with the development of the bone mass: The Amsterdam Growth And Health Longitudinal Study. Bone, 27(6), 847-853.

Kim, S., So, W. Y., Kim, J., \& Sung, D. J. (2016). Relationship between Bone-Specific Physical Activity Scores and Measures for Body Composition and Bone Mineral Density in Healthy Young College Women. PloS one, 11(9), e0162127.

Kohrt, W. M., Ehsani, A. A., \& Birge, S. J. (1997). Effects of Exercise Involving Predominantly Either Joint-Reaction or Ground-Reaction Forces on Bone Mineral Density in Older Women. Journal of Bone and Mineral Research, 12(8), 1253-1261.

Kwan, M. Y., Cairney, J., Faulkner, G. E., \& Pullenayegum, E. E. (2012). Physical activity and other health-risk behaviors during the transition into early adulthood: A longitudinal cohort study. American Journal of Preventive Medicine, 42(1), 14-20.

Kyle, U. G., Morabia, A., Schutz, Y., \& Pichard, C. (2004). Sedentarism affects body fat mass index and fat-free mass index in adults aged 18 to 98 years. Nutrition, 20(3), 255260.

Li, J., \& Siegrist, J. (2012). Physical activity and risk of cardiovascular disease: A meta-analysis of prospective cohort studies. International Journal of Environmental Research and Public Health, 9(2), 391-407.

Liu, L., Maruno, R., Mashimo, T., Sanka, K., Higuchi, T., Hayashi, K., Shirasaki, Y., Mukai, N., Saitoh, S., \& Tokuyama, K. 
(2003). Effects of physical training on cortical bone at midtibia assessed by peripheral QCT. Journal of Applied Physiology, 95(1), 219-224.

Maltais, M. L., Desroches, J., \& Dionne, I. J. (2009). Changes in muscle mass and strength after menopause. Journal of Musculoskelet Neuronal Interact, 9(4), 186-97.

Morseth, B., Emaus, N., Wilsgaard, T., Jacobsen, B. K., \& Jørgensen, L. (2010). Leisure time physical activity in adulthood is positively associated with bone mineral density 22 years later. The Tromsø study. European Journal of Epidemiology, 25(5), 325-331.

Newman, A. B., Kupelian, V., Visser, M., Simonsick, E. M., Goodpaster, B. H., Kritchevsky, S. B., Tylavsky, F. A., Rubin, S. M., \& Harris, T. B. (2006). Strength, but not muscle mass, is associated with mortality in the health, aging and body composition study cohort. The Journals of Gerontology, 61(1), 72-77.

Newman, A. B., Lee, J. S., Visser, M., Goodpaster, B. H., Kritchevsky, S. B., Tylavsky, F. A., Nevitt, M., \& Harris, T. B. (2005). Weight change and the conservation of lean mass in old age: the Health, Aging and Body Composition Study. The American Journal of Clinical Nutrition, 82(4), 872-878.

Nilsson, M., Ohlsson, C., Eriksson, A. L., Frändin, K., Karlsson, M., Ljunggren, Ö., Mellström, D., \& Lorentzon, M. (2008). Competitive physical activity early in life is associated with bone mineral density in elderly Swedish men. Osteoporosis International, 19(11), 1557-1566.

Nordin, B. C., Need, A. G., Steurer, T., Morris, H. A., Chatterton, B. E., \& Horowitz, M. (1998). Nutrition, osteoporosis, and aging. Annals of the New York Academy of Sciences, 854(1), 336-351.

Ogden, C. L., Carroll, M. D., Curtin, L. R., McDowell, M. A., Tabak, C. J., \& Flegal, K. M. (2006). Prevalence of overweight and obesity in the United States, 1999-2004. Journal of American Medical Association, 295(13), 1549-1555.

Riebe, D., Blissmer, B. J., Greaney, M. L., Ewing Garber, C., Lees, F. D., \& Clark, P. G. (2009). The relationship between obesity, physical activity, and physical function in older adults. Journal of Aging and Health, 21(8), 1159-1178.

Sacheck, J. M., Kuder, J. F., \& Economos, C. D. (2010). Physical fitness, adiposity, and metabolic risk factors in young college students. Medicine and Science in Sports and Exercise, 42(6), 1039-1044.

Saraví, F. D., \& Sayegh, F. (2013). Bone mineral density and body composition of adult premenopausal women with three levels of physical activity. Journal of Osteoporosis, 2013.

Sattelmair, J., Pertman, J., Ding, E. L., Kohl, H. W., Haskell, W., \& Lee, I. M. (2011). Dose response between physical activity and risk of coronary heart disease. Circulation Journal, CIRCULATIONAHA-110.

Smith, S. C. (2011). Reducing the global burden of ischemic heart disease and stroke: A challenge for the cardiovascular community and the United Nations. Circulation, 124(3), 278-279.

Sui, X., LaMonte, M. J., \& Blair, S. N. (2007). Cardiorespiratory fitness as a predictor of nonfatal cardiovascular events in asymptomatic women and men. American Journal of Epidemiology, 165(12), 1413-1423.

Thompson, D. L., Rakow, J., \& Perdue, S. M. (2004). Relationship between accumulated walking and body composition in middle-aged women. Medicine and Science in Sports and Exercise, 36(5), 911-914.

Tuna, H. D., Edeer, A. O., Malkoc, M., \& Aksakoglu, G. (2009). Effect of age and physical activity level on functional fitness in older adults. European Review of Aging and Physical Activity, 6(2), 99.

Weeks, B. K., \& Beck, B. R. (2008). The BPAQ: A bonespecific physical activity assessment instrument. Osteoporosis International, 19(11), 1567-1577.

Weeks, B. K., Hirsch, R. D., Moran, D. S., \& Beck, B. R. (2011). A useful tool for analysing the effects of bone-specific physical activity. Salud (i) Ciencia, 18(6), 538-542.

Weeks, B. K., Purvis, M., \& Beck, B. R. (2016). Physical activity estimated by the bone-specific physical activity questionnaire is also associated with cardiovascular risk. European Journal of Sport Science, 16(8), 1204-1211.

World Health Organization. (2011). Physical inactivity: A global public health problem. Retrieved March 21, 2011, http://www. who.int/dietphysicalactivity/factsheet_inactivity/en/

Yusuf, S., Reddy, S., Ounpuu, S., \& Anand, S. (2001). Global burden of cardiovascular diseases: Part I: General considerations, the epidemiological transition, risk factors, and impact of urbanization. Circulation, 104, 2746-2753. 


\section{신체활동수준에 따른 젊은 성인 여성의 신체구성, 골밀도 및 건강관련체력 비교}

\section{심수정 - 김성우 · 송종국 · 강효정 (경희대학교)}

〔목적〕 본 연구의 목적은 젊은 성인 여성의 신체활동수준에 따라 신체구성, 골밀도 및 건강관련체력의 차이 를 비교하는데 있다. (방법) 연구대상자는 만 19-29세의 여성 90명이 연구에 참여하였으며, 뼈 관련 신체활 동 설문지 $(\mathrm{BPAQ})$ 의 신체활동수준에 따라 세 그룹(낮은, 중간, 높은 신체활동그룹) 각 30명씩 나뉘었다. 신 체구성과 골밀도는 DXA(Hologic, QDR-4500, USA)를 이용하여 측정하였다. 건강관련체력은 유연성(앉 아윗몸앞으로굽히기), 근력(악력), 근지구력(윗몸일으키기), 심폐지구력(최대산소섭취량)을 측정하였다. 모든 자료는 SAS 9.4 버전으로 분석하였으며, 평균과 표준편차를 제시하였다. 신체활동수준에 따른 차이를 비교하 기 위하여 일원분산분석을 실시하였고, 사후 분석은 Duncan' multiple range test 방법을 사용하였다. 모은 통계적 유의 수준은 .05로 설정하였다. (결과〕 첫째, 제지방량 $(\mathrm{F}=8.364, p=.0001)$ 에서 신체활동량이 낮 은 그룹은 중간 그룹과 높은 그룹의 여성들보다 통계적으로 유의하게 낮았다. 둘째, 전신 골밀도 $(\mathrm{F}=16.730$, $p=.0001)$, 요추 골밀도 $(\mathrm{F}=11.480, p=.0001)$, 대퇴 골밀도 $(\mathrm{F}=42.182, p=.0001)$, 전완 골밀도 $(\mathrm{F}=5.560, p=.005)$ 에서 세 그룹 간 통계적으로 유의한 차이가 나타났다. 셋째, 건강관련체력의 경우 악력 과 최대심박수에서 세 그룹 간 통계적으로 유의한 차이가 나타나지 않았으나, 앉아윗몸앞으로굽히기 $(\mathrm{F}=11.433$, $p=.0001)$, 윗몸일으키기 $(\mathrm{F}=17.972, p=.0001)$, 최대산소섭취량 $(\mathrm{F}=3.106, p=.05)$, 운동시간 $(\mathrm{F}=$ $7.479, p=.001$ )에서 신체활동이 높은 그룹이 통계적으로 유의하게 높았다. (결론) 본 연구에서 $\mathrm{BPAQ}$ 를 이 용한 신체활동 조사는 젊은 성인 여성의 골밀도와 건강관련체력의 차이를 규명할 수 있었으나, 체지방률, 체지 방량과 WHR의 관련성을 분석하는데 다소 미흡한 것으로 나타났다. 따라서 본 연구에서 사용한 설문지는 유 산소운동 혹은 저항성운동을 포함하는 다양한 운동유형에 참여 여부를 판단할 수 없었기 때문에 나타난 것으 로 판단되며, 추후 연구에서는 다양한 신체활동 유형을 고려한 종단연구가 필요할 것으로 사료된다.

주요어: 뼈-관련 신체활동 설문지, 신체구성, 골밀도, 건강관련체력 